\title{
Infection, Colonization, and Disease of Amaranthus hybridus Leaves by the Alternaria tenuissima Group
}

\author{
J. T. Blodgett, Former Post-Doctoral Fellow, and W. J. Swart, Professor, Department of Plant Science, University \\ of the Free State, P.O. Box 339, Bloemfontein 9300, South Africa
}

\section{ABSTRACT}

Blodgett, J. T., and Swart, W. J. 2002. Infection, colonization, and disease of Amaranthus hybridus leaves by the Alternaria tenuissima group. Plant Dis. 86:1199-1205.

With the increased use of Amaranthus hybridus as a leafy-vegetable crop in Africa and the recent identification of Alternaria leaf spot on this host in southern Africa, the role of this potentially damaging pathogen was investigated. The goals of this study were to test the pathogenicity of the Alternaria tenuissima group, determine how these fungi infect Amaranthus hybridus leaves, and examine the colonization pattern within host tissues. Asymptomatic leaves of Amaranthus hybridus were collected from two field sites in South Africa. Eight $A$. tenuissima group isolates collected from these leaves were used in inoculation experiments conducted in both greenhouse and growth chamber studies. Scanning electron microscopy revealed A. tenuissimalike conidia germinating on leaf surfaces and mycelia entering leaves only through stomata of both field-collected and artificially inoculated leaves. Unwounded, inoculated leaves had no symptoms, and light-microscopy observations of both asymptomatic field-collected and unwounded and inoculated leaves revealed hyphae in mesophyll tissue growing intercellularly with no host cell penetration or host-cell response. Seven of the eight isolates produced brown to black, circular to oval, necrotic lesions only at the wound site of injured and inoculated leaves. These results confirm that isolates of the A. tenuissima group can infect and colonize Amaranthus hybridus leaves in a manner consistent with other endophytic fungi, and suggest that these fungi can act as latent leaf pathogens when the host is altered by wounding.

Additional keywords: amaranth, asymptomatic persistence, environmental conditions, latent pathogen, smooth amaranthus, wound response

Amaranthus species are dicotyledonous pseudocereals identified as alternative crops with potential for expanded commercial application $(15,22)$. The leaves and seeds of these species are edible and are high in vitamins $\mathrm{A}$ and $\mathrm{C}$, calcium, iron, protein, carbohydrates, and lipids $(19,22)$. Amaranthus hybridus (common names: smooth amaranthus or amaranth) can grow up to $1.5 \mathrm{~m}$ tall, produce a large amount of biomass in a short time, and complete up to six generations per year. This species is a nutritious leafy vegetable well suited for cultivation in semiarid regions throughout the world.

It has been postulated that all living plants contain fungi that live within their tissues without causing any visible symptoms on their hosts. These fungi are called endophytes, and they display varying degrees of association and nutritional interdependence with their host plants, including positive, neutral, or even negative relationships $(20,28,35,36)$. Possible bene-

Corresponding author: J. T. Blodgett; Current address: USDA-Forest Service, Forest Health Management, 1730 Samco Rd., Rapid City, SD 57702; E-mail: jblodgett@fs.fed.us

Accepted for publication 30 May 2002.

Publication no. D-2002-0912-01R

(C) 2002 The American Phytopathological Society fits of endophytes to plants can include antagonism to fungal pathogens and a decrease in palatability of plant tissues for herbivorous insects and large animal herbivores. This suggests mutualistic relationships between various plants and their associated endophytic fungi. Some grass endophytes have been shown to provide protection from insects and pathogenic fungi $(12,16,28)$. On the other hand, some endophytic fungi can act as pathogens when induced by certain environmental or nutritional conditions, or by host maturity $(35,36)$. However, if the stressful environmental or host condition never occurs, these fungi complete their life cycle after the host dies, thus never causing disease.

Alternaria tenuissima-like species are both endophytes and latent pathogens of Amaranthus hybridus. The A. tenuissima group consists of the most common fungi isolated from asymptomatic, surfacedisinfested leaves of Amaranthus hybridus collected from the field in South Africa (8). This group was represented by more than $85 \%$ of the isolates collected from leaves, but was seldom recovered from the leaves of greenhouse-grown plants (less than $0.2 \%$ ). Brown to black, circular to oval, necrotic lesions were observed on leaves of cultivated, 6-month-old Amaranthus hybridus plants in Potchefstroom, South Africa, in 1998; and members of the $A$. tenuissima group were isolated frequently from the lesions (7). In artificial inoculation tests, the A. tenuissima group caused leaf-spot symptoms comparable to those observed in the field.

Although small leaf spots might be of minor importance on many vegetable crops, Amaranthus hybridus is a leafyvegetable crop. Even a few small spots can cause complete economic losses. This complete crop loss has only been observed at two sites in South Africa, where nearly every leaf on every plant in two fields had minor to extensive leaf-spot symptoms.

The increased use of Amaranthus hybridus as a leafy vegetable necessitates the understanding of the fungi associated with this host and their potential roles as both endophytes and pathogens. The objectives of this study were to: (i) test if isolates of the A. tenuissima group can act as latent pathogens, (ii) examine if water stress or wounding stimulates infection/colonization, and (iii) determine how endophytic fungi infect Amaranthus leaves and the subsequent colonization pattern within leaf tissues. Field and greenhouse observations and microscopic examinations using both asymptomatic field-collected leaves and artificially inoculated leaves were used to examine the A. tenuissima-Amaranthus hybridus relationship.

\section{MATERIALS AND METHODS}

Greenhouse pathogenicity experiments. Smooth amaranthus plants were established in 500-ml pots in a soil mix (vol/vol) of $50 \%$ sand-loam (10 to $15 \%$ clay) and $50 \%$ peat moss. Soils were steam-sterilized twice for $1 \mathrm{~h}$ at $80^{\circ} \mathrm{C}$ before planting seeds $10 \mathrm{~mm}$ deep. Plants were watered to field capacity daily and were fertilized by adding $50 \mathrm{ml}$ per pot of a 3 g/liter hydroponic nutrient solution (6.5:2.7:13 N:P:K with micronutrients) once a week as a soil drench. Six-week-old plants were transplanted into 2-liter pots containing the same soil mix as the 500-ml pots.

Two weeks after transplanting, plants were supplemented with artificial light to provide a 16-h photoperiod. Photon flux density of the supplemented light averaged $18 \mu \mathrm{E} \cdot \mathrm{s}^{-1} \cdot \mathrm{m}^{-2}$, with a maximum recorded ambient greenhouse photon flux density of $1,233 \mu \mathrm{E} \cdot \mathrm{s}^{-1} \cdot \mathrm{m}^{-2}$. The average greenhouse temperature was $25^{\circ} \mathrm{C}$ during the day and $17^{\circ} \mathrm{C}$ at night, and the average relative humidity (RH) was $78 \%$ during the day and $94 \%$ at night. The floors and walls of the greenhouse were sprayed with water 
twice a day, 7 days a week, to maintain the high RH. Plants were placed on a bench flooded with water to allow continuous water contact with the bottom of the pots.

For the first greenhouse experiment, seven replications per combined treatment were used. Combined treatments consist of all combinations of five inoculation treatments (including a mock inoculation), two water treatments, and two high humidity treatments (time in plastic bags). All combined treatments were assigned randomly, and the experiments were repeated in two independent trials 7 weeks apart. Therefore, a completely randomized experimen- tal design was used in the analyses.

Four weeks after transplanting (midApril and early June for the repetition, 1998), half the plants (70 plants per trial) were placed on stands suspending them above the water (water stressed), and the remaining plants were allowed continuous water contact with the bottom of the pots (non-water-stressed). A pressure bomb (26) was used periodically to measure the mean predawn leaf water potentials $\left(\psi_{\mathrm{PD}}\right)$ of five randomly selected plants of each water treatment. When the mean $\psi_{\mathrm{PD}}$ of the water-stressed plants fell below -2.0 MPa, all plants were watered to field capacity. A

Table 1. Origin of the single-spore Alternaria tenuissima group isolates used to inoculate Amaranthus hybridus leaves ${ }^{\mathrm{a}}$

\begin{tabular}{lccc}
\hline Isolate $^{\mathbf{b}}$ & Date collected & Geographic origin & Experiment $^{\mathbf{c}}$ \\
\hline 2 & 11 April & Bloemfontein & ND \\
46 & 11 April & Bloemfontein & D \\
130 & 11 April & Bloemfontein & NMD \\
157 & 11 April & Bloemfontein & D \\
224 & 25 April & Potchefstroom & D \\
279 & 25 April & Potchefstroom & NWMD \\
297 & 25 April & Potchefstroom & ND \\
321 & 25 April & Potchefstroom & D \\
\hline
\end{tabular}

${ }^{a}$ All isolates were collected in South Africa from individual, asymptomatic Amaranthus hybridus leaves in 1997.

${ }^{\mathrm{b}}$ Culture collection numbers.

${ }^{\mathrm{c}} \mathrm{N}=$ isolate was used in the nonwounded greenhouse inoculation experiment. $\mathrm{W}=$ isolate was used in the wounded greenhouse inoculation experiment. $\mathrm{M}=$ leaves inoculated with the isolate were examined with both the scanning electron and light microscopes. $\mathrm{D}=$ isolate was used in the detached-leaf assay experiment.

Table 2. Percentages of inoculated Amaranthus hybridus leaves with symptoms and percentages of leaves from which the Alternaria tenuissima group was recovered ${ }^{\mathrm{a}}$

\begin{tabular}{|c|c|c|}
\hline $\begin{array}{c}\text { Experiment } \\
\text { Treatment }\end{array}$ & Symptoms $(\%)^{\mathbf{b}}$ & $\begin{array}{l}\text { A. tenuissima group } \\
\text { recovery }(\%)^{\mathbf{c}}\end{array}$ \\
\hline \multicolumn{3}{|c|}{ Nonwounded greenhouse experiment } \\
\hline Inoculated $^{\mathrm{d}}, 16 \mathrm{~h}^{\mathrm{e}}$ & 0 & 0 \\
\hline Inoculated $^{\mathrm{d}}, 3$ days $^{\mathrm{e}}$ & 0 & 72 \\
\hline Control, $16 \mathrm{~h}^{\mathrm{e}}$ & 0 & 0 \\
\hline Control, 3 days ${ }^{\mathrm{e}}$ & 0 & 2 \\
\hline \multicolumn{3}{|l|}{ Wounded greenhouse experiment } \\
\hline Wounded $^{\mathrm{f}}$ and inoculated $\mathrm{d}^{\mathrm{d}}$ & 82 & 71 \\
\hline Nonwounded and inoculated ${ }^{\mathrm{d}}$ & 0 & 73 \\
\hline Wounded $\mathrm{f}^{\mathrm{f}}$ controls & 0 & 2 \\
\hline Nonwounded controls & 0 & 0 \\
\hline \multicolumn{3}{|l|}{ Detached-leaf assay } \\
\hline Wounded ${ }^{f}$ and inoculated ${ }^{g}$ & 56 & 95 \\
\hline Nonwounded and inoculated ${ }^{g}$ & 0 & 60 \\
\hline Wounded ${ }^{f}$ controls & 0 & 0 \\
\hline Nonwounded controls & 0 & 0 \\
\hline
\end{tabular}

a All single-spore isolates were collected in South Africa from individual, asymptomatic Amaranthus hybridus leaves in 1997. For the greenhouse experiments, results are pooled across trials and across water treatments since those main effects were not significant. For the detached-leaf assay, results are pooled across trials. Although there were differences between the two trials in lesion size, the trial-inoculation treatment interaction was not significant, indicating a similar relative response among isolates between trials.

b Symptoms included dark brown to black, circular to oval, necrotic lesions. Larger lesions had tan centers, and tissues beside the leaf spots remained green.

${ }^{c}$ The presence of A. tenuissima group isolates in leaves was confirmed from two surface-disinfested 5-mm-diameter leaf disks.

${ }^{\mathrm{d}}$ Inoculated with conidial suspensions at $10^{5}$ conidia per $\mathrm{ml}$.

e After inoculation, plants were placed in plastic bags for $16 \mathrm{~h}$ or 3 days.

${ }^{\mathrm{f}}$ Leaves were wounded with a needle $(0.5 \mathrm{~mm}$ diameter) at leaf centers (midvein; equal distance from leaf tip and leaf base).

g A 5-mm-diameter, colonized potato dextrose agar plug cut from the margin of an actively growing culture was placed mycelium-side-down on the center of the leaf (midvein; equal distance from leaf tip and leaf base).
$\psi_{\mathrm{PD}}$ of $-2.0 \mathrm{MPa}$ was reached twice in both trials.

Cultures of four single-spore A. tenuissima group isolates (Table 1), collected previously from asymptomatic Amaranthus hybridus leaves (8), were grown on V8 juice agar in petri plates for 3 weeks at ambient room temperature (approximately $24^{\circ} \mathrm{C}$ ) in the dark. These isolates were randomly selected. Culture plates then were washed several times with cold, sterile distilled water from flasks on ice. A glass rod was used to agitate cultures with water between each wash. The conidial suspensions, decanted from plates, were filtered through two layers of cheesecloth, collected in cold sterile flasks, and diluted to $10^{5}$ conidia per ml. Noncolonized plates containing V8 juice agar were washed in a similar manner, and the extract was used for controls. Conidial suspensions were maintained in iced flasks for approximately $1 \mathrm{~h}$ before inoculation.

After 1 week under the different watering regimes (i.e., water-stressed or nonstressed), conidial suspensions of each of the four isolates and the V8 juice agar extract (control) were applied to five leaves of each of 14 stressed and 14 nonstressed plants. The tops and bottoms of inoculated leaves were saturated with approximately $1.3 \mathrm{ml}$ of conidial suspension (or control) using an atomizer, while covering the remainder of the plant with plastic to prevent cross-contamination. The conidial suspensions also were applied to $1.5 \%$ water agar (WA; Oxoid, Basingstoke, England) plates to test conidial germination, which ranged from 96 to $100 \%$. Leaves were allowed to dry between subsequent leaf inoculations on a plant. Plants were then sealed in plastic bags. Metal loops were placed in the pots to suspend the plastic bags above and around the plants. Half the bags (70 plants per trial) from each water treatment were removed after $16 \mathrm{~h}$ and the other half after 3 days.

In a second greenhouse experiment, seven replications per combined treatment were used. Combined treatments consist of all combinations of one inoculation or mock inoculation treatment, the two water treatments, and a wounded or nonwounded leaf treatment. All combined treatments were assigned randomly, and the experiments were repeated in two independent trials 7 weeks apart. Therefore, a completely randomized experimental design was used in the analyses.

The second greenhouse experiment was conducted at the same time and in the same greenhouse as the first experiment. The same methods were used with three exceptions: in this experiment, one single-spored isolate (no. 279; Table 1) and the control were applied to four individual leaves (two inoculated and two control leaves) of each of seven water-stressed and seven nonstressed plants per trial; all plastic bags were removed after 3 days; and half of the 

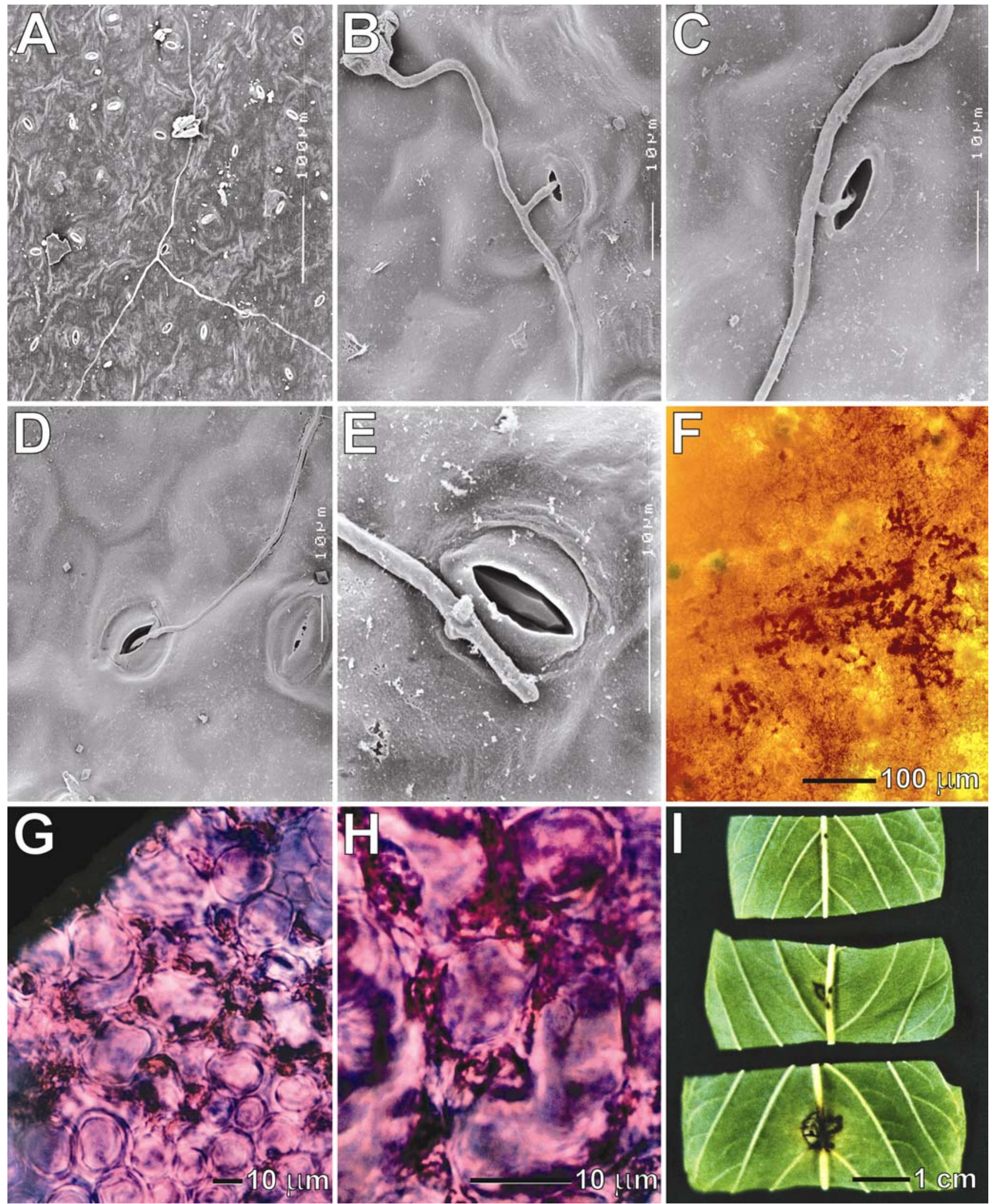

Fig. 1. Scanning electron micrographs of Alternaria tenuissima-like conidia germinating on the epidermal surface of Amaranthus hybridus leaves collected from A, the field, and $\mathbf{B}$, an inoculated greenhouse experiment. Scanning electron micrographs of $\mathbf{C}$, the 90 degree hyphal branching associated with the A. tenuissima group stomatal entry, D, direct growth into a stomata, and $\mathbf{E}$, the 90 degree hyphal branching with no stomatal entry on Amaranthus hybridus leaves collected from an inoculated greenhouse experiment. Light micrographs of the A. tenuissima group internal hyphal net around Amaranthus hybridus leaf mesophyll tissues collected from the field and $\mathbf{F}$, unstained at $\times 100$, G, stained with acid fuchsin-malachite green at $\times 400$, and $\mathbf{H}$, collected from an inoculated greenhouse experiment and stained with acid fuchsin-malachite green at $\times 1,000$. A camera photo of $\mathbf{I}$, the range of symptoms observed on wounded and inoculated greenhouse leaves. 
inoculated and control leaves were wounded with a needle $(0.5 \mathrm{~mm}$ diameter $)$ at leaf centers (midvein; equal distance from leaf tip and leaf base) after the conidial suspension or control was applied. Leaves were allowed to dry between subsequent leaf inoculations on a plant, and before wounding. The isolate was randomly selected.

For both greenhouse experiments, leaf lesions were counted and the diameters were measured (if present) 4 weeks after inoculation. All leaves then were surfacedisinfested in a series of $1 \mathrm{~min}$ in $96 \%$ ethanol, $5 \mathrm{~min}$ in a $3.5 \% \mathrm{NaOCl}$ solution (wt/vol), and $30 \mathrm{~s}$ in $96 \%$ ethanol. Two leaf disks ( $5 \mathrm{~mm}$ diameter) were then cut from each leaf using a cork-borer. One leaf disk was taken from the leaf center, and the other disk was centered $12 \mathrm{~mm}$ lateral to the leaf center. The disks were transferred to WA and incubated at ambient laboratory temperature (approximately $24^{\circ} \mathrm{C}$ ) and light. The presence of the A. tenuissima group was confirmed after 21 days from resulting conidia. Leaves inoculated with two of the single-spore isolates (Table 1) and control leaves were saved from the greenhouse experiments for later microscopic observations.

Lesion diameters were analyzed by fourfactor analysis of variance with all interactions. Factors used as main effects were: (i) inoculation treatment (isolate and control treatments); (ii) watering regime (waterstressed and non-water-stressed treatments); (iii) trial (trial 1 and 2); and (iv) either the high humidity treatment $(16 \mathrm{~h}$ or 3 days in plastic bags) for the first greenhouse experiment, or the wounded/ nonwounded treatment for the second greenhouse experiment. Lesion diameters were analyzed both untransformed and after natural- $\log (x+1)$ and $\operatorname{sqrt}(x+1)$ transformations were applied. The $P$ values and resulting conclusions were similar for all forms of analysis. Therefore, results are reported only for the untransformed data. $\psi_{\mathrm{PD}}$ from the two experiments were analyzed by one-way analysis of variance with watering regime as the factor. Chi-square analysis was used to analyze recovery of the A. tenuissima group in relation to watering regime. Analysis of variance (using general linear model procedure) and chisquare analysis were performed using Minitab for Windows, release 10.2 (Minitab Inc., State College, PA).

Microscopic observations. Fields were sampled from two sites (20 km apart) in Bloemfontein, South Africa, in 1997. One noninoculated, asymptomatic Amaranthus hybridus leaf was collected from each of 12, 6-month-old plants from each site for later microscopic observations. Our previous study (8) confirmed the presence of the A. tenuissima group in noninoculated, surface-disinfested, asymptomatic Amaranthus hybridus leaves. The A. tenuissima group was isolated from $88 \%$ of 1,000 asymptomatic leaf tissues sampled at one of the sites in 1997 (8), and from $86 \%$ of 100 asymptomatic leaf tissues sampled at the other site the same year using the same isolation methods (J. T. Blodgett and W. J. Swart, unpublished).

For surface observations (infection patterns), leaf pieces $(5 \times 5 \mathrm{~mm})$ from both the field and the greenhouse experiments were examined using scanning electron microscopy (SEM). Twelve leaf pieces were examined from each of the two fields, and eight leaf pieces were examined from each of the greenhouse experiments for both an inoculated and control treatment. Immediately after collecting, the tissues were fixed in cold $\left(4^{\circ} \mathrm{C}\right) 3 \%$ glutaraldehyde in a $0.1 \mathrm{M}$ sodium-phosphate buffer (pH 7.0). Tissues were fixed for approximately 2 months in the dark at $4^{\circ} \mathrm{C}$. The leaf pieces then were dehydrated in a graded ethanol series to $100 \%$ ethanol (50, $70,80,95$, and 2 times at $100 \%$ ); criticalpoint dried in liquid $\mathrm{CO}_{2}$ from $100 \%$ ethanol (Polaron Critical Point Dryer Circulatot C400; Polaron Equipment Limited, Watford, England); attached to aluminum stubs with two-way tape; and sputtercoated with gold (SEM sputter coater unit E5000; Polaron Equipment Limited). Leaf pieces were then examined with a scanning electron microscope (JEOL WINSEM JSM-6400 Scanning Microscope; JEOL Limited, Tokyo, Japan) at $5 \mathrm{kV}$.

For confirmation of fungal mycelium within host tissues (colonization patterns) and also surface observations, leaf pieces $(10 \times 10 \mathrm{~mm})$ from both the field and the greenhouse experiments were examined using light microscopy. Twelve leaf pieces were examined from each of the two fields, and eight leaf pieces were examined from each of the greenhouse experiments for both an inoculated and control treatment. Immediately after collecting, the tissues were fixed in cold $\left(4^{\circ} \mathrm{C}\right)$ ethanol: dichlormethane $(3: 1 \mathrm{vol} / \mathrm{vol})$ with $0.15 \%$ trichloroacetate. Tissues were fixed for approximately 2 months in the dark at $4^{\circ} \mathrm{C}$. The leaf pieces then were cleared in nearly saturated chloral hydrate $(5: 2 \mathrm{wt} / \mathrm{vol})$ and stored in $50 \%$ glycerol with trace lactophenol at $4^{\circ} \mathrm{C}$ in the dark. Leaf pieces were stained for $24 \mathrm{~h}$ with acid fuchsin-malachite green (1), which stains fungal mycelia bluish-purple. The stained pieces were placed on glass slides, covered with coverslips, and viewed at $\times 100, \times 400$, and $\times 1,000$ using a blue filter (NCB10) mounted before the light source. Fixed, cleared, but unstained leaf pieces also were examined.

Detached-leaf assay. Smooth amaranthus plants were established in 500-ml pots according to procedures described for the greenhouse experiments. Plants were watered to field capacity daily and were fertilized according to procedures described for the greenhouse experiments. Leaves from 6-week-old A. tenuissima-free plants were then collected from the greenhouse.
Seven replications per combined treatment were used. Combined treatments consist of all combinations of 10 inoculation treatments (including a mock inoculation and a nontreated control leaf), and either a wounded or nonwounded leaf treatment. All combined treatments were assigned randomly, and the experiments were repeated in two independent trials 8 weeks apart. Therefore, a completely randomized experimental design was used in the analyses.

Eight single-spore A. tenuissima group isolates (Table 1) were randomly selected for pathogenicity tests from a previous field experiment (8). Ten leaves were placed in each of 14 sterile, clear plastic, moist chambers $(24.5 \times 24.5 \times 2.5 \mathrm{~cm}$; A/N Nunc, Roskilde, Denmark). For each of the eight isolates, one 5-mm-diameter, colonized potato dextrose agar plug (PDA; Oxoid) cut from the margin of an actively growing culture was placed myceliumside-down on the center of a leaf (midvein; equal distance from leaf tip and leaf base). A sterile PDA plug was used as a control, as was an untreated leaf (no plug). Half the leaves from each inoculation treatment were wounded with a needle $(0.5 \mathrm{~mm}$ diameter) at leaf centers before placement of the PDA plugs. The moist chambers were placed in plastic bags, and the bags were tied closed. Sealed chambers were then placed in a growth chamber set at $25^{\circ} \mathrm{C}$ during the day and $20^{\circ} \mathrm{C}$ at night, and provided artificial light (photon flux density $13 \mu \mathrm{E} \cdot \mathrm{s}^{-1} \cdot \mathrm{m}^{-2}$ ) for $16 \mathrm{~h} /$ day.

Leaf lesions were counted and the diameters were measured (if present) 4 weeks after inoculation. Isolations were then made from all leaves, and the presence of the A. tenuissima group was confirmed as described in the greenhouse experiments.

Lesion diameters were analyzed by three-factor analysis of variance with interactions. Factors used as main effects were: (i) inoculation treatment (isolate and control treatments), (ii) wounded/nonwounded treatment, and (iii) trial (trial 1 and 2). Lesion diameters were analyzed both untransformed and after natural- $\log (x+1)$ and $\operatorname{sqrt}(x+1)$ transformations were applied. The $P$ values and resulting conclusions were similar for all forms of analysis. Therefore, results are reported only for the untransformed data. Analyses of variance (using general linear model procedure) were performed using Minitab for Windows, release 10.2 (Minitab Inc., State College, PA).

\section{RESULTS}

Greenhouse pathogenicity experiments. All unwounded, artificially inoculated leaves remained green and asymptomatic in both greenhouse experiments. All wounded and unwounded controls also remained green and asymptomatic in both greenhouse experiments. However, symp- 
toms were observed on $82 \%$ of the wounded and inoculated leaves (Table 2). Symptoms were only observed at the wound site of wounded and inoculated leaves, and were first observed after 18 and 17 days (trials 1 and 2, respectively). The isolate produced dark brown to black, circular to oval, necrotic lesions with diameters ranging from $<1 \mathrm{~mm}$ up to $7 \mathrm{~mm}$, with an average diameter of $3.1 \mathrm{~mm}(0.7$ standard error). Larger lesions had tan centers, and tissues adjacent to the leaf spots remained green. Symptoms were the same as those previously observed in the field in which species of the A. tenuissima group were identified as the causal agent of disease in this host (7). The inoculation treatment effect (control versus isolate) for lesion size was significant $(P<0.001)$, but not the trial effect $(P=0.159)$ or the trialinoculation treatment interaction effects $(P$ $=0.872$ ).

Significant differences in water potentials $(P<0.001$ for all comparisons $)$ between plants of the two watering regimes were measured in both trials of both greenhouse experiments. The lowest water potential readings (before watering) of stressed plants averaged $-2.1 \mathrm{MPa}$ in both trials of both experiments, and the nonstressed plants averaged $-0.1 \mathrm{MPa}$ for all readings. However, the effect of water treatment was not significant on lesion size $(P=0.631)$ for wounded, inoculated leaves. The effect of water treatment also was not significant on the recovery of fungi ( $P=1.000,0.285$, and 0.704 ; nonwounded experiment with plastic bags for $16 \mathrm{~h}$ or 3 days, and wounded experiment, respectively).

In the first greenhouse experiment, the A. tenuissima group was recovered from leaves of the unwounded and inoculated plants that were sealed in plastic bags for 3 days. The A. tenuissima group was recovered from $68 \%$ of the leaves sampled at the leaf center and from $55 \%$ of the leaves sampled $12 \mathrm{~mm}$ from the leaf center, with a total recovery of $72 \%$ (Table 2). However, the A. tenuissima group was never recovered from unwounded, inoculated leaves that were kept at high $\mathrm{RH}$ for only $16 \mathrm{~h}$. For wounded and inoculated leaves, the A. tenuissima group isolate was recovered from $69 \%$ of the leaves sampled at the wound site and from $20 \%$ of the leaves sampled $12 \mathrm{~mm}$ from the leaf center (beyond the symptomatic areas), with a total recovery of $71 \%$. For nonwounded inoculated leaves in the second greenhouse experiment, the $A$. tenuissima group was recovered from a total of $73 \%$ of the leaves. The A. tenuissima group was seldom recovered from control plants in either greenhouse experiment.

Microscopic observations. Surface examinations, using both SEM and light microscopy, revealed A. tenuissima-like conidia germinating and resultant mycelial growth on leaf surfaces of the field- collected leaves (both sites) and on the artificially inoculated greenhouse leaves (Fig. 1A and B). Hyphae were observed entering leaves only through stomata, and this was only observed on the fieldcollected leaves (both field sites) and on leaves from the greenhouse experiments when plants were maintained at high $\mathrm{RH}$ for 3 days. Hyphae were never observed penetrating epidermal tissues, and appressoria were never observed. Stomatal entry was observed as often as six times on a single $5 \times 5 \mathrm{~mm}$ field-collected leaf section and as often as 12 times on a single $5 \times 5$ $\mathrm{mm}$ inoculated greenhouse leaf section. A 90 degree hyphal branching pattern was associated with approximately $80 \%$ of the observed stomatal entries (Fig. 1B and C); however, direct growth into stomata was also observed (Fig. 1D). For artificially inoculated greenhouse leaves, when plants were maintained at high RH for only $16 \mathrm{~h}$, A. tenuissima-like conidia were observed germinating on leaf surfaces with mycelial growth; however, stomatal entry was never observed. Still, the 90 degree hyphal branching was observed at the stomata (Fig. 1E). Fungal hyphae were never observed on surfaces of control leaves.

Light microscopy (internal leaf observations) revealed a net of hyphae surrounding mesophyll tissues in field-collected leaves from both sites (Fig. 1F and G). A similar net of hyphae surrounding mesophyll tissues (Fig. 1H) was observed in leaves from the artificially inoculated, unwounded leaves in the greenhouse experiment, but only when the plants were maintained at high RH for 3 days. Hyphae were growing only intercellularly among the mesophyll tissues, with no host cell penetration and no observed host cell response. Tissue colonization was never observed in the artificially inoculated, unwounded greenhouse plants maintained at high $\mathrm{RH}$ for only $16 \mathrm{~h}$, and fungal hyphae were never observed in control leaves.

For the inoculated and wounded leaves in the greenhouse experiment, tissues around the wounds were collapsed and colonized (Fig. 1I). Internal examinations at the wound sites were not possible using our techniques because tissues remained dark brown and opaque. Extensive mycelial growth was observed on leaf surfaces around the wounds, and A. tenuissima-like conidia were observed germinating on the leaf surfaces.

Detached-leaf assay. Unwounded, inoculated leaves and both wounded and unwounded controls remained green and asymptomatic. However, symptoms were observed on $56 \%$ (Table 2) of the wounded and inoculated leaves (excluding one isolate that did not produce symptoms). Symptoms were only observed at the wound site of wounded and inoculated leaves, and were first observed after 14 and 12 days (trials 1 and 2, respectively). Seven of the eight isolates produced dark brown to black, circular to oval, necrotic lesions with diameters ranging from $<1$ $\mathrm{mm}$ up to $7 \mathrm{~mm}$ (average diameter $2.4 \mathrm{~mm}$ [0.5 standard error] in trial $1 ; 3.0 \mathrm{~mm}[0.7$ standard error] in trial 2). Leaf-spot symptoms were comparable to those observed in the greenhouse wound-inoculation experiment and to those previously observed in the field (7). One isolate (no. 321; Table 1) never produced symptoms in either trial.

Differences in lesion diameters were significant $(P=0.002)$ among inoculation treatments; however, when only the seven isolates that produced symptoms were included in the analyses, inoculation treatment was not significant $(P=0.682)$. Although there were differences between the two trials in lesion size $(P=0.013)$, the trial-inoculation treatment interaction was not significant $(P=0.234)$, indicating a similar relative response among isolates between trials.

For unwounded and inoculated leaves, the A. tenuissima group was recovered from $60 \%$ of the leaves sampled at the leaf center (inoculation site) and from $13 \%$ of the leaves sampled $12 \mathrm{~mm}$ from the leaf center, with a total recovery of $60 \%$ (Table $2)$. For wounded, inoculated leaves, the $A$. tenuissima group was recovered from $93 \%$ of the leaves sampled at the wound site and from $32 \%$ of the leaves sampled $12 \mathrm{~mm}$ from the leaf center (beyond the symptomatic areas), with a total recovery of $95 \%$. For the isolate that never produced symptoms, recovery from wounded, inoculated leaves averaged $92 \%$ from the wound site and $46 \% 12 \mathrm{~mm}$ from the leaf center, with a total recovery of $93 \%$. The A. tenuissima group was never recovered from unwounded or wounded controls.

\section{DISCUSSION}

Endophytic fungi have been reported to infect hosts either through stomata or by direct epidermal penetration (23). Epidermal penetration may include the formation of appressoria on leaf surfaces and infection pegs through the epidermis. Many pathogenic Alternaria species can penetrate the cuticle and epidermis directly, but others only enter through the stomata or seem to require wounds (24). Consistent with the greenhouse experiments, we found higher Alternaria recovery at leaf centers compared with leaf margins from fieldcollected Amaranthus hybridus leaves (J. T. Blodgett and W. J. Swart, unpublished). These recovery differences might be attributed to the higher frequency of stomata at leaf centers compared with leaf margins on this host. Our current study indicates that infection of Amaranthus hybridus by the A. tenuissima group is restricted to entry through stomata of unwounded leaves, but may also occur through wounds.

Duration of high humidity and/or wetting of leaf surfaces are important factors in determining infection success or failure. 
Although these factors have been extensively studied for various foliar pathogenic fungi, little research has been conducted with endophytic fungi. For endophytic fungi, the more humid microclimate within a tree crown compared with the edge of the crown was suggested to account for higher recovery of endophytes within the crown (13). The minimum wetting periods reported for infection by different pathogenic Alternaria species range from 3 to $73 \mathrm{~h}$ (24). Our results suggest that high RH for more than $16 \mathrm{~h}$, but possibly less than $72 \mathrm{~h}$, is required for both germinating and subsequent infection of Amaranthus hybridus leaves by the A. tenuissima group.

The surface-disinfestation methods used in this study are consistent with those used in other studies of endophytic fungi. In the greenhouse experiment, when leaves were kept at high RH for $16 \mathrm{~h}$, conidia and hyphae were on leaf surfaces; yet there was no infection or colonization of leaves and no Alternaria recovery. Recovery of other fungal species is also extremely rare from noninoculated, surface-disinfested Amaranthus hybridus leaves of plants grown in a greenhouse (8). Our results clearly show that the surface-disinfestation methods used in this study are sufficient to kill fungi growing on Amaranthus hybridus leaf surfaces.

Infection and colonization patterns of fungi can be diagnostic in determining the organisms present in a host. Both intercellular and intracellular colonization of host tissues by endophytes have been described for other hosts (23). Cabral et al. (10) describe several forms of host colonization in field-collected Juncus and correlate the various forms to the frequencies of fungal recovery. In the current study, observations of both artificially inoculated leaves and field-collected leaves using both SEM and light microscopy revealed the same results. There was only one common pattern of host infection and colonization in both the field and artificially inoculated leaves. The net of hyphae surrounding mesophyll tissues and the 90 degree hyphal branching pattern at the stomata are unique, yet were frequently observed in or on leaves. This is also consistent with the single, dominant $A$. tenuissima group recovered from leaves of this host at two field sites in South Africa (8). Therefore, isolates belonging to the $A$. tenuissima group are clearly the dominant fungal species in asymptomatic field leaves. The minor species previously reported in leaves of this host (8) might be restricted to substomatal chambers, as was observed for some fungal species in annual Juncus (10).

Although A. tenuissima is found on a wide range of plants and is extremely common, it has never been previously identified in high frequencies from asymptomatic host tissues. It was previously shown that A. alternata occurs in low frequencies in Juncus spp. and Phaseolus spp. with little host colonization $(10,18)$. In contrast, isolation frequencies of A. tenuissima isolates from Amaranthus hybridus leaves collected from the field were as high as $88 \%$ (8), and extensive colonization occurs in this host. The unique colonization pattern of the A. tenuissima group isolates in unwounded leaf tissues of Amaranthus hybridus and the high recovery of this fungus suggests a strong specificity of this fungus with this host. This internal net of hyphae in asymptomatic leaves has never been previously reported for $A$. tenuissima on any host. These results are consistent with the conclusions of Petrini (20), who suggested that a limited number of endophytic fungal taxa dominate within a single plant species.

Environmental conditions including water stress are known to influence many plant diseases. Drought stress is associated with enhancement of disease development on several species by many pathogens (2$4,6,21,25)$. However, water stress also may have a neutral or negative influence on the development of certain plant diseases $(5,14,33,34)$. Alternaria diseases can be enhanced by high or low soil moisture extremes (24). A field survey of tree endophytes (11) found lower frequencies of endophytic fungi from leaves on dry sites than on sites of moderate moisture. We found that the abundance of endophytic fungi in Amaranthus hybridus is influenced by changes in the soil environment, and potentially by soil moisture (J. T. Blodgett and W. J. Swart, unpublished). Stomatal closure reduces water loss and might result in reduced host infection. Since infection of unwounded leaves occurs only through the stomata in this host-fungus system, infection can occur if water potentials are not too extreme and leaf surfaces are exposed to very high RH, such as in the early phases of our greenhouse experiments.

Wounding can trigger disease expression and might result in increased infection. However, it is clear from both the fieldcollected leaves and from the unwounded, inoculated experimental leaves that infection and colonization do not require wounding. Without wounding, though, no symptoms develop. Therefore, wounding causes quick changes in the host-fungal system, resulting in a leaf-spot disease. It might simply be the momentary nutritional imbalance in the system that is quickly overcome, resulting in the distinct leaf spot. The recovery of the A. tenuissima group in asymptomatic tissues beyond the leaf spot in both the greenhouse experiments and the detached-leaf assay show that colonization does occur beyond the symptomatic area.

This leaf-spot disease was previously reported on this host from a field in South Africa, and the A. tenuissima group was identified as the causal agent with the same range of symptoms as in this present study (7). Wounding resulting from wind and sand damage have been attributed to increased disease of potato, tomato, and onion leaves by various Alternaria spp. $(9,17)$. Skiles (32) found that Alternaria porri can infect unwounded onion leaves, but causes more disease when the tissues are damaged. Injury was suggested as a requirement for infection by $A$. alternata and $A$. tenuissima, two weak pathogens of onion (32). Feeding damage by the bean leaf beetle (Cerotoma trifurcata) has also been associated with disease of soybean pods caused by A. tenuissima (27).

Alternaria is prevalent in unwounded Amaranthus hybridus, yet leaves appear completely healthy. Our results confirm that the A. tenuissima group can infect and colonize Amaranthus hybridus leaves in a manner consistent with other endophytic fungi or latent pathogens. However, in this host-pathogen relationship, infection and colonization does occur in nonwoundedinoculated leaves, yet no symptoms develop. This asymptomatic persistence of pathogenic fungi may be more common than is generally believed in other hostpathogen systems.

The same range of symptoms was observed on wounded leaves in both the detached-leaf assay for seven of eight isolates, and for one isolate in the second greenhouse experiment (wounded leaves). Five distinct morphological forms of $\mathrm{Al}$ ternaria were previously identified from this host (8), the most common belonging to the A. tenuissima group. This species grouping is further divided into temporary subgroupings $(29,30,31)$. Differences observed in pathogenicity might be helpful in further examinations of the A. tenuissima group. The detached-leaf assay offers a relatively easy method to screen isolates of the A. tenuissima group quickly, and potentially to screen susceptible/resistant species and varieties of Amaranthus.

The definition of endophytic fungi used in this paper does not exclude endophytic fungi acting as latent pathogens. The $A$. tenuissima group in Amaranthus hybridus seems to fit both the endophytic and the latent pathogen lifestyle (depending on host condition). Extensive asymptomatic colonization (growing intercellularly) with no host cell penetration and no symptoms is not typical of most pathogens. The disease is not typical of most endophytic fungi. Therefore, at least some isolates of the A. tenuissima group do persist asymptomatically in Amaranthus hybridus, yet when triggered by wounding can act as pathogens.

\section{ACKNOWLEDGMENTS}

We thank S. Nameth and L. Rhodes for presubmission reviews, and anonymous reviewers for their many helpful suggestions. Assistance with the scanning electron microscope by R. Verhoeven and P. van Wyk, and with the compound microscope by C. Bender, was greatly appreciated. We also thank P. Mohasi, Z. van der Linde, M. Islam, and M. Molemela for technical assistance. Finan- 
cial support was provided by the National Research Foundation (former Foundation for Research Development) of South Africa.

\section{LITERATURE CITED}

1. Alexander, M. P. 1980. A versatile stain for pollen, fungi, yeast, and bacteria. Stain Technol. 55:13-18.

2. Appel, D. N., and Stipes, R. J. 1984. Canker expansion on water-stressed pin oaks colonized by Endothia gyrosa. Plant Dis. 68:851853.

3. Bagga, D. K., and Smalley, E. B. 1974. The development of hypoxylon canker of Populus tremuloides: Role of interacting environmental factors. Phytopathology 64:658-662.

4. Bertrand, P. F., English, H., Uriu, K., and Schick, F. J. 1976. Late season water deficits and development of Cytospora canker in French prune. Phytopathology 66:1318-1320.

5. Biggs, A. R., Davis, D. D., and Merrill, W. 1983. Cutting development and restriction of wound-associated infection in Populus. Can. J. Plant Pathol. 5:269-272.

6. Blodgett, J. T., Kruger, E. L., and Stanosz, G. R. 1997. Effects of moderate water stress on disease development by Sphaeropsis sapinea on red pine. Phytopathology 87:422-428.

7. Blodgett, J. T., Swart, W. J., and Chen, W. 1999. First report of Alternaria tenuissima as a leaf pathogen of Amaranthus hybridus. Plant Dis. 83:878.

8. Blodgett, J. T., Swart, W. J., Louw, S. vdM., and Weeks, W. J. 2000. Species composition of endophytic fungi in Amaranthus hybridus leaves, petioles, stems, and roots. Mycologia 92:853-859.

9. Bock, K. R. 1964. Purple blotch (Alternaria porri) of onion in Kenya. Ann. Appl. Biol. 54:303-311.

10. Cabral, D., Stone, J. K., and Carroll, G. C. 1993. The internal mycobiota of Juncus spp.: Microscopic and cultural observations of infection patterns. Mycol. Res. 97:367-376.

11. Carroll, G. C., and Carroll, F. E. 1978. Studies on the incidence of coniferous needle endophytes in the Pacific Northwest. Can. J. Bot. 56:3034-3043.

12. Clay, K. 1989. Clavicipitaceous endophytes of grasses: Their potential as biocontrol agents. Mycol. Res. 92:1-12.

13. Helander, M. L., Neuvonen, S., and Ranta, H. 1996. Natural variation and effects of anthropogenic environmental changes on endophytic fungi in trees. Pages 197-207 in: Endophytic Fungi in Grasses and Woody Plants: Systematics, Ecology, and Evolution. S. C. Redlin and L. M. Carris, eds. American Phytopathological Society, St. Paul, MN.

14. Jacobi, W. R., and Riffle, J. W. 1989. Effects of water stress on Thyronectria canker of honeylocusts. Phytopathology 79:1333-1337.

15. Kauffman, C. S., and Weber, L. E. 1990. Grain amaranth. Pages 127-139 in: Advances in New Crops. Proc. Nat. Sympos. New Crops, Res., Development, Economics. 1st. J. Janick and J. E. Simon, eds. Timber Press, Portland, OR.

16. Latch, G. C. M., Hunt, W. F., and Musgrave, R. R. 1985. Endophyte fungi affect growth of perennial ryegrass. N.Z. J. Agric. Res. 28:165-168.

17. Moore, W. D. 1942. Some factors affecting the infection of tomato seedlings by Alternaria solani. Phytopathology 32:399-403.

18. O'Donnell, J., and Dickinson, C. H. 1980. Pathology of Alternaria and Cladosporium isolates on Phaseolus. Trans. Br. Mycol. Soc. 74:335-342.

19. Oomen, H. A. P. C., and Grubben, G. J. H. 1978. Tropical Leaf Vegetables in Human Nutrition. Communication 69, Dep. Agric. Res., Royal Tropical Institute, Amsterdam, Netherlands. Orphan Publishing Co., Willemstad, Curacao.

20. Petrini, O. 1996. Ecological and physiological aspects of host specificity in endophytic fungi. Pages 87-100 in: Endophytic Fungi in Grasses and Woody Plants: Systematics, Ecology, and Evolution. S. C. Redlin and L. M. Carris, eds. American Phytopathological Society, St. Paul, MN.

21. Pusey, P. L. 1989. Influence of water stress on susceptibility of nonwounded peach bark to Botryosphaeria dothidea. Plant Dis. 73:10001003.

22. Rawate, P. D. 1983. Amaranth (pigweed): A crop to help solve the world protein shortage. Pages 287-298 in: Environmentally Sound Agriculture: Selected Papers from the Fourth
International Conference of the Internationa Federation of Organic Agriculture Movements. A. W. Lockeretz, ed. Praeger, NY.

23. Redlin, S. C., and Carris, L. M. 1996. Endophytic Fungi in Grasses and Woody Plants: Systematics, Ecology, and Evolution. American Phytopathological Society, St. Paul, MN.

24. Rotem, J. 1994. The Genus Alternaria: Biology, Epidemiology, and Pathogenicity. American Phytopathological Society, St. Paul, MN.

25. Schoeneweiss, D. F. 1981. The role of environmental stress in diseases of woody plants. Plant Dis. 65:308-314.

26. Scholander, P. F., Hammel, H. T., Edda, D. Bradstreet, E. D., and Hemmingsen, E. A 1965. Sap pressure in vascular plants. Science 148:339-346.

27. Shortt, B. J., Sinclair, J. B., Helm, C. G., Jeffords, M. R., and Kogan, M. 1982. Soybean seed quality losses associated with bean leaf beetles and Alternaria tenuissima. Phytopathology 72:615-618.

28. Siegel, M. R., Latch, G. C. M., and Johnson, M. C. 1987. Fungal endophytes of grasses. Annu. Rev. Phytopathol. 25:293-315.

29. Simmons, E. G. 1990. Alternaria themes and variation (27-53). Mycotaxon 37:79-119.

30. Simmons, E. G. 1995. Alternaria themes and variation (112-144). Mycotaxon 55:55-163.

31. Simmons, E. G., and Roberts, R. G. 1993. Alternaria themes and variation 73. Mycotaxon 48:109-140.

32. Skiles, R. L. 1953. Purple and brown blotch of onion. Phytopathology 43:409-412.

33. Swart, W. J., Conradie, E., Wingfield, M. J., and Venter, W. B. 1992. Effects of water stress on the development of cambial lesions caused by Cryphonectria cubensis on Eucalyptus grandis. Plant Dis. 76:744-746.

34. Tippett, J. T., Crombie, D. S., and Hill, T. C. 1987. Effect of phloem water relations on the growth of Phytophthora cinnamomi in Eucalyptus marginata. Phytopathology 77:246 250.

35. Verhoeff, K. 1974. Latent infection by fungi. Annu. Rev. Phytopathol. 12:99-110.

36. Wilson, D. 1995. Endophyte-the evolution of a term, and clarification of its use and definition. Oikos 73:274-276. 